\section{First detection of human dirofilariasis in South Africa}

\author{
Krishnee Moodley, ${ }^{1,2}$ Chetna N. Govind, ${ }^{1,2}$ \\ Abdool K.C. Peer, ${ }^{1,2}$ \\ Marissa van der Westhuizen, ${ }^{3}$ \\ Dharmesh Parbhoo, ${ }^{2,3}$ Lisa Ming Sun, ${ }^{4}$ \\ Desiree C. du Plessis, ${ }^{4}$ John A. Frean ${ }^{4,5}$ \\ ${ }^{1}$ Lancet Laboratories, Durban; ' 2 chool of \\ Health Sciences, University of KwaZulu- \\ Natal; ${ }^{3}$ Medical Practitioner, Durban; \\ ${ }^{4}$ National Institute for Communicable \\ Diseases, Johannesburg; ${ }^{5}$ Wits Research \\ Institute for Malaria, Faculty of Health \\ Sciences, University of the \\ Witwatersrand, Johannesburg, South \\ Africa
}

\section{Abstract}

Humans are occasionally inadvertently infected with dirofilariae, the zoonotic nematodes. We report two cases of human dirofilariasis in South Africa, an area apparently nonendemic for this infection. Dirofilariasis is frequently misdiagnosed, so increased awareness of this entity in areas that are non-endemic is essential for prevention of inappropriate investigations and invasive therapy.

\section{Introduction}

Human dirofilariasis is a zoonotic filarial nematode infection caused by members of the genus Dirofilaria (order Spiurida). The most frequently implicated dirofilariae, of more than 24 species, are D. immitis and D. repens. ${ }^{1}$ A wide variety of natural definitive hosts includes canines and felines, both wild and domestic. $^{2}$ There are two main groups of Dirofilaria spp. parasites - those that inhabit the heart and blood vessels of the natural host (e.g.D. immitis, agent of heartworm disease of dogs), and those that live in the subcutaneous tissues (e.g. D. repens, causing subcutaneous infection in dogs and cats). ${ }^{1,2}$ The mammalian hosts are infected via mosquito vectors. Mosquitoes implicated in transmission are mainly Aedes and Culex species, but also include members of other genera (Armigeres, Anopheles, and Mansonia). ${ }^{3}$ Infective larvae gain access to human tissues when the vector feeds, and mature into the adult stage over several months, typically presenting as ocular, subcutaneous or pulmonary reactive nodules containing the worms. The presence of microfilariae in the blood is not a feature of human infections. Most worms found in humans are sexually immature and solitary. In patent infections in the natural animal host, bloodstream microfilariae are the infective stage for the mosquito intermediate host and vector.

Globally, dirofilariasis is widespread but the geographic distribution of individual Dirofilaria species varies. While $D$. immitis affects animal and human hosts in tropical and temperate regions in many parts of the world (excluding southern Africa), D. repens is limited to the Old World, including Africa. ${ }^{2}$ In South Africa, a few cases have been reported in animals but the detection of the first local human dirofilariasis cases, as described here, demonstrates the need for increased awareness of the clinical presentation of this infection in apparently non-endemic areas of the world. ${ }^{4,5}$ To our knowledge these are the first cases of human dirofilariasis described in South Africa.

\section{Case Report \#1}

A 63-year-old female, residing in KwaZuluNatal Province, South Africa, presented to her general practitioner with temporal headaches, a cystic conjunctival swelling and itchiness of the left eye, which had started 2 days prior to presentation. Her previous medical history was unremarkable. She had travelled to Europe, during the month before presentation, visiting the Czech Republic for 2 days, Poland for 14 days and England for 11 days.

Clinical examination revealed a normal right eye, with an obvious conjunctival mass on the inferomedial aspect of the left eye. There was minimal surrounding inflammation. The clear sac-like swelling contained a large, white coiled mass (Figure 1) that was mobile, but remained localised during the examination. The rest of the ocular examination was normal.

The patient had a limbal conjunctival peritomy performed, in theatre. A slender, white worm was removed completely and submitted to the laboratory for identification. The sac from which the worm was removed appeared to be well-defined and encapsulated. Post-operatively, the patient recovered well with no further sequelae.

The macroscopic appearance was that of a slender nematode, measuring $69 \mathrm{~mm}$ by 0.56 $\mathrm{mm}$ (Figure 2A). The identification was confirmed microscopically as Dirofilaria species on the morphological criteria of a simple head structure without obvious appendages, and prominent multiple longitudinal cuticular ridges on a transversely-cut fragment of the body (Figure 2B).

Molecular identification was performed according to published methods. ${ }^{6}$ Briefly, DNA was extracted using a Macherey-Nagel NucleoSpin Tissue DNA kit (Duren, Germany).
Correspondence: Krishnee Moodley, Lancet Laboratories Kwa-Zulu Natal, P0 Box 48066, Qualbert 4078, South Africa.

Tel: +27.313.086610.

E-mail: krishnee.moodley@lancet.co.za

Key words: Dirofilaria repens, zoonotic filariasis, ocular dirofilariasis, South Africa.

Acknowledgements: authors thank the Microbiology Laboratory staff at Lancet Laboratories, Durban, South Africa.

Contributions: KM co-conceived and drafted the report; CNG assisted with drafting the report; AKCP co-conceived and assisted with review and drafting of the report; MvdW and DP treated the patient and provided clinical information; LMS performed initial parasitological identification; DCdP performed molecular identification; JAF performed histopathological identification, coconceived and assisted with drafting the report.

Conflict of interests: the authors declare no potential conflict of interests.

Conference presentation: the cases were presented at the UniPath Congress, September 2014, Pretoria, South Africa.

Received for publication: 19 November 2014.

Revision received: 8 January 2015.

Accepted for publication: 9 January 2015.

This work is licensed under a Creative Commons Attribution NonCommercial 3.0 License (CC BYNC 3.0).

(C) Copyright K. Moodley et al., 2015

Licensee PAGEPress, Italy

Infectious Disease Reports 2015; 7:5726

doi:10.4081/idr.2015.5726

All PCR products were visualised on a $1.5 \%$ agarose gel (Figure 3). Pan-filarial primers were used to amplify a sequence from the $5.8 \mathrm{~S}$ $28 \mathrm{~S}$ region in the first-round confirmation of a filarial worm, producing the 542-bp fragment typical of $D$. repens. The sample was then subjected to species-specific amplification of a 5SrRNA gene sequence of $D$. repens, which resulted in 2 PCR bands, as previously described, although the larger product was somewhat smaller (175 bp) than expected (247 bp); the smaller product was the anticipated 153 bp in size (Figure 3). Both of these PCR products were Sanger sequenced in forward and reverse directions and BLASTed against the Genbank database. The only matches were to $D$. repens, the best being $100 \%$ match of the $175 \mathrm{bp}$ product to a $5 \mathrm{SrRNA}$ sequence from Italian strains (Genbank accession no. AJ242966), and 95\% match of the 153 bp amplicon to a presumed Indian strain 5SrRNA sequence (Genbank accession no. KC429771). 


\section{Case Report \#2}

A 57-year-old woman, resident in a town east of Johannesburg, Gauteng Province, South Africa, complained of a swelling in the right groin. Prior to her presentation, she had travelled to the coastal city of Richards Bay, on the KwaZulu-Natal Province's north coast. There was no international travel history. A subcutaneous nodule was excised and submitted for histopathological examination. Sections showed fibrofatty tissue and foreign body granulomas, with the presence of giant cells, lymphocytes, plasma cells and a few neutrophils. Sections of a female parasitic nematode were present, identified as a Dirofilaria species on the basis of prominent longitudinal cuticular ridges, large lateral chords, internal lateral ridges, and typical coelomyarian muscle cell arrangement and gut and reproductive organs (Figure 2B,C). The average spacing between the cuticular ridges was $11.6 \mu \mathrm{m}$, consistent with published descriptions of $D$. repens (namely, about $12 \mu \mathrm{m}$ ). ${ }^{7}$

\section{Discussion}

Human dirofilariasis presents typically as subcutaneous or ocular masses (D. repens), or as pulmonary nodular lesions ( $D$. immitis). Recently, however, more atypical sites have been reported where $D$. immitis has been found in cranial, hepatic and intra-ocular tissue, while $D$. repens has been identified from the lungs, scrotum, penis and female mammary glands. ${ }^{2}$

The clinical presentation varies from asymptomatic to sometimes fatal. ${ }^{8}$ Transient reactive swelling to migrating parasites may occur before they localise to produce inflammatory masses. Nodular lesions may be misdiagnosed as tumors. Ocular dirofilariasis may be mimicked by Onchocerca lupi infection,

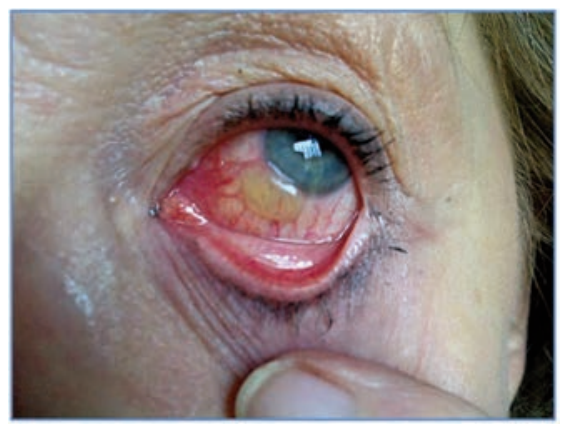

Figure 1. Cystic lesion on inferomedial aspect of the left eye. another zoonotic filariasis. Typically, a cystic lesion is noted either subconjunctivally, as in this case, or in other structures of the eye. ${ }^{8}$ The definitive host for 0 . lupi are dogs, and human infection has been reported in Europe. ${ }^{9}$ In South Africa ocular loiasis, caused by the filarial nematode Loa loa, has been diagnosed in immigrants from West and Central Africa, but it has a different clinical presentation. The adult worm moves across the eye under the conjunctiva over the course of a few hours, and the transient inflammation and swelling subsides as the worm leaves the area and continues its subcutaneous migration. ${ }^{1}$

Morphology and geographical distribution has been the traditional method of dirofilarial species determination. The diameter of the nematode and prominent longitudinal ridges in our cases make the most likely identification to be $D$. repens, as $D$. immitis has a smooth cuticle. Other species with obvious cuticular ridges (D. ursi, D. tenuis, D. subder$m a t a)$ are only found in North America. ${ }^{7}$ The geographical distribution of $D$. repens includes Africa. Although the recent travel history for the first patient included Europe, where $D$. repens infections are well described, the relatively slow rate of development of the dirofilarial nematodes indicates that the infection was acquired before her trip to Europe. Unequivocal molecular identification of D.repens was demonstrated in this case; a possible intraspecies variant was suggested by a smaller than anticipated 5SrRNA amplicon, but this needs to be further investigated and confirmed. ${ }^{6}$ Although suitable hosts and vectors for $D$. immitis are present in South Africa, the only known cases in dogs in this country have been imported. ${ }^{4}$ Human $D$. immitis infections have not been reported. There is limited evidence that dog heartworm occurs in Mozambique, ${ }^{10}$ and it is known to be present in Tanzania and Kenya. ${ }^{11,12}$ A report of subcutaneous dirofilariasis from Zimbabwe,,$^{13}$ was subsequently shown on morphological grounds to be infection by an Onchocerca species (J. Frean, personal communication). Cases of $D$. repens in a South African dog and cat suggest that occasional local human cases can be expected. ${ }^{5,14}$ A few cases of human dirofilariasis acquired elsewhere in Africa have been published. ${ }^{15,16}$

Species identification of dirofilariae may be challenging. The worm is not always submitted as a whole specimen, or may have been damaged at surgery. Immature, dead and degenerate worms in biopsies may not be identifiable. Some morphological features are shared between zoonotic Dirofilaria species, confounding definitive identification in histological sections. ${ }^{3}$ Geographical distribution may change over time, with climatic changes potentially affecting vector distribution, and global travel with pets occurring more frequently. ${ }^{9}$ Adjunctive diagnostic laboratory methods include serological tests, such as

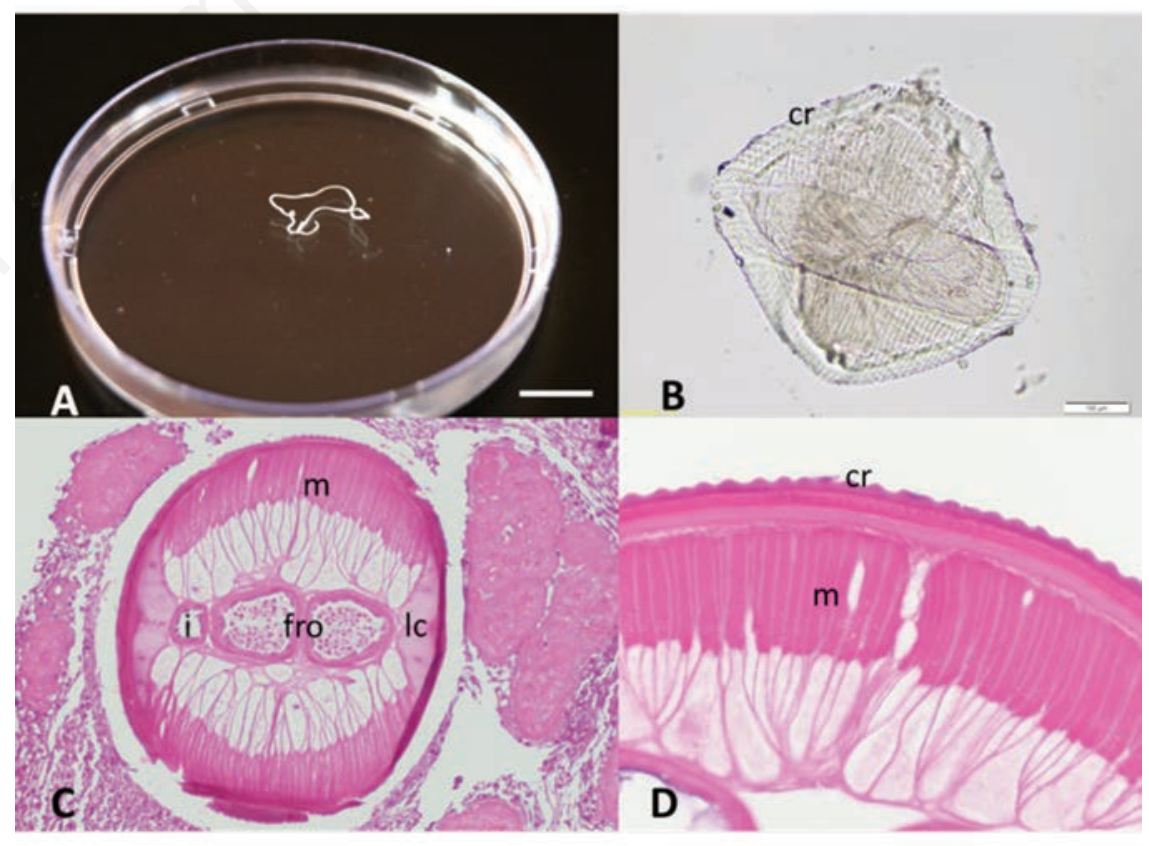

Figure 2. A) Case 1. Macroscopic view of filarial nematode. Bar=15 mm. B) Case 1. Transverse section of nematode, unstained, showing cuticular ridges (cr). Bar $=0.1 \mathrm{~mm}$. C) Case 2. Transverse section of nematode, H\&E stain, showing coelomyarian mucles cells $(\mathrm{m})$, lateral chords $(\mathrm{lc})$, female reproductive organs (fro), and intestine (i). Original magn. 100×. D) Case 2. Transverse section, H\&E stain, showing coelomyarian muscle cells $(\mathrm{m})$ and prominent cuticular ridges $(\mathrm{cr})$. Original magnification $400 \times$. 


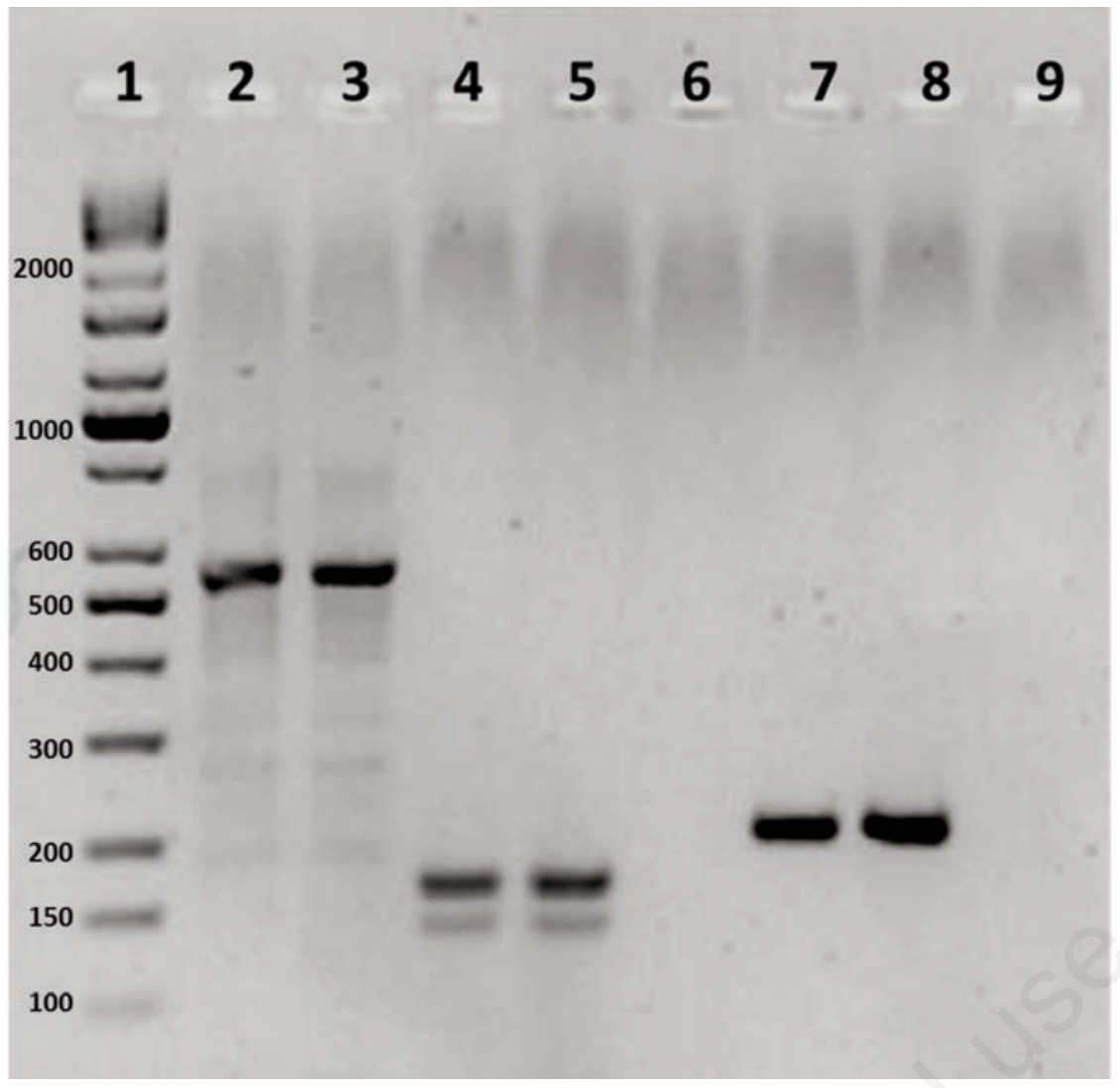

Figure 3. Case 1, molecular identification of filarial worm; $1.5 \%$ agarose gel. Lane 1: DNA fragment size markers (bp); Lanes 2 and 3: panfilarial sequence (ribosomal intergenic and ITS2 regions); Lanes 4 and 5: D. repens small ribosomal subunit intergenic region, showing 2 bands; Lanes 7 and 8: D. repens cytochrome oxidase subunit I sequence; Lanes 6 and 9: negative PCR controls.

enzyme-linked immunosorbent assays (ELISAs), and molecular tests. ${ }^{2}$ DNA amplification and sequencing methods have the highest specificity, with the advantage of not requiring a complete or mature worm for species identification. ${ }^{3}$

Anti-helminthic therapy is not recommended for human dirofilariasis, as surgery is adequate. ${ }^{2}$ Some cases of ocular dirofilariasis have resolved without any intervention. ${ }^{8}$ Correct diagnosis is imperative in these patients, as misdiagnosis may lead to unnecessary chemotherapy and extensive surgery.

\section{Conclusions}

Human dirofilariasis is uncommon, and therefore lack of awareness of this entity amongst clinicians frequently results in misdiagnosis and underestimation of the actual disease burden. There is a lack of seroprevalence data for dirofilariasis in animals in South Africa. Seroprevalence studies, for determination of disease burden in animals in South Africa, where prevalence is unknown, but host, vector and appropriate environmental conditions are present, may be useful.

Increased awareness of disease burden in the natural reservoir in the country and of the clinical entity of human dirofilariasis can prevent inappropriate chemotherapeutic and surgical interventions for patients.

\section{References}

1. Orihel TC, Ash LR. Parasites in human tissues. Chicago: American Society of Clinical Pathologists; 1995.

2. Simón F, Siles-Lucas M, Morchón R, et al. Human and animal dirofilariasis: the emergence of a zoonotic mosaic. Clin Microbiol Rev 2012;25:507-44.
3. Cancrini G, Kramer L, eds. Insect vectors of dirofilaria species. In: Heartworm infection in humans and animals. Salamanca: Ediciones Universidad de Salamanca; 2001. pp 63-82.

4. Verster A, Cilliers WJ, Schroeder H. A case of heartworm (Dirofilaria immitis) in an imported dog and a report of the occurrence of canine microfilariae in the Republic of South Africa. J S Afr Vet Assoc 1991;62:33-4.

5. Schwan EV, Miller DB, de Kock D, van Heerden A. Dirofilaria repens in a cat with acute liver failure. J S Afr Vet Assoc 2000;71:197-200.

6. Rishniw M, Barr SC, Simpson KW, et al. Discrimination between six species of canine microfilariae by a single polymerase chain reaction. Vet Parasitol 2006;135:303-14.

7. Gutierrez Y. Diagnostic pathology of parasitic infections with clinical correlations. 2nd ed. New York: Oxford University Press; 2000.

8. Genchi C, Kramer LH, Rivasi F. Dirofilarial infections in Europe. Vector Borne Zoonotic Dis 2011;11:1307-17.

9. Otranto D, Dantas-Torres F, Brianti E, et al. Vector-borne helminths of dogs and humans in Europe. Parasit Vectors 2013;6:16.

10. Schwan EV, Durand DT. Canine filariosis caused by Dirofilaria immitis in Mozambique: a small survey based on the identification of microfilariae. J S Afr Vet Assoc 2002;73:124-6.

11. Bwangamoi O, Frank H. The incidence and pathology of Dirofilaria immitis infection in dogs in Nairobi. J Small Anim Prac 1970;11:293-300.

12. Magayuka SA. Development of filarial parasites in mosquitos in north-east Tanzania. Bull World Health Organ 1973;49:110-11.

13. Goldsmid JM, Bettiol S. A probable case of subcutaneous dirofilariasis acquired in Zimbabwe. Ann Australasian Coll Trop Med 2002;3:16.

14. Bredal WP, Gjerde B, Eberhard ML, et al. Adult Dirofilaria repens in a subcutaneous granuloma on the chest of a dog. J Small Anim Pract 1998;39:595-7.

15. Awadalla HN, Bayoumi DM, Ibrahim IR. The first case report of suspected human dirofilariasis in the eyelid of a patient from Alexandria. J Egypt Soc Parasitol 1998;28:941-3.

16. Orihel TC, Helentjaris D, Alger J. Subcutaneous dirofilariasis: single inoculum, multiple worms. Am J Trop Med Hyg 1997;56:452-5. 